\title{
Challenges Faced by Multidrug-Resistant Tuberculosis Patients in Three Financially Affluent Chinese Cities
}

This article was published in the following Dove Press journal: Risk Management and Healthcare Policy

\author{
Peize Zhang $\mathbb{D}^{1, *}$ \\ Guanghui $\mathrm{Xu}^{2}$,* \\ Yanhua Song ${ }^{3, *}$ \\ Jie $\operatorname{Tan}^{\prime}$ \\ Tao Chen' \\ Guofang Deng' \\ 'Department of Pulmonary Medicine \& \\ Tuberculosis, The Third People's Hospital \\ of Shenzhen, Shenzhen, People's Republic \\ of China; ${ }^{2}$ Jiangmen Institute of \\ Tuberculosis Prevention and Control, \\ Guangdong, People's Republic of China; \\ ${ }^{3}$ Department of Tuberculosis, Chest \\ Hospital of Peking, Beijing, People's \\ Republic of China \\ *These authors contributed equally to \\ this work
}

Purpose: The aim of this study was to analyze socioeconomic burdens and other difficulties that multidrug-resistant tuberculosis (MDR-TB) patients in cities are facing, to identify major obstacles and which groups of patients are most affected.

Methods: Face-to-face and phone-call interviews were conducted in early 2018 to follow-up with patients newly diagnosed with MDR-TB in 2017 in three tuberculosis hospitals in three financially affluent Chinese cities. Demographic data and information on their medical care, insurance coverage, and medical expenses were collected and analyzed.

Results: A total of 144 newly diagnosed MDR-TB cases were reviewed during the study period, excluding 38 who were lost to follow-up and 29 patients who refused to participate, 77 patients were enrolled in this study. A total of 61 (79\%) of these patients were hospitalized after MDR-TB diagnosis with an average hospital stay of 14 days, of them 57 (74\%) were sputum positive on diagnosis. The proportion of patients who failed community care were $48 \%$ married, $56 \%$ in white collar employment and $43 \%$ in temp jobs/unemployed. In terms of insurance coverage, the proportion of patients who failed community care were $23 \%$ with no insurance and/or New Rural Co-operative Medical Care Scheme (NRCMS) and 45\% with Urban Employee Basic Medical Insurance (UEBMI)/Urban Residents Basic Medical Insurance (URBMI) and commercial insurance. Difficulties patients encountered were, financial pressure (33\%), psychological stress (26\%), adverse drug reactions $(23 \%)$, repulsive reaction to injections $(17 \%)$. Fourty-eight percent of the patients spent over $¥ 2000$ (USD300) per month on TB treatment.

Conclusion: Despite insurance coverage, financial hardship remains the number one difficulty MDR-TB patients encountered in relatively financially affluent cities. Among them, the married working class were found to be the most financially sensitive group and have the highest tendency to fail community care. It is of utmost urgency to enhance the current medical policy to improve treatment adherence.

Keywords: socioeconomic burden, MDR-TB, patient care, financial support, catastrophic cost, treatment adherence

\section{Introduction}

Tuberculosis (TB) is a pressing public health problem affecting millions of people globally every year and China is one of the high caseload countries. Even worse, China is among the top burden countries of multidrug-resistant tuberculosis (MDR-TB). ${ }^{1}$ MDR-TB is a situation where the causative bacteria of TB develop resistance to at least isoniazid and rifampicin, the two most powerful anti-TB drugs. ${ }^{1}$ Provision of care and support for these patients, and disease control have become more challenging and a top priority concern with a growing number of MDR-TB cases.
Correspondence: Guofang Deng Email jxxk1035@yeah.net

Risk Management and Healthcare Policy 2020:I3 2387-2394 
It has been long-proventhat for infectious disease, poverty is a major obstacle to a cure, and impoverishment can lead to adverse effects to disease control. ${ }^{2}$ The China government has introduced various measures to help combat poverty resulting from medical treatment. The three Government-subsidized insurance programs were the result of a nation-wide health system reform. ${ }^{3-5}$ The New Rural Co-operative Medical Care Scheme (NRCMS) targets at rural populations including farmers and the low-income groups. Cost of insurance is CNY30 (USD4.5)/year (minimal) to make it affordable for the rural poor. ${ }^{6,7}$ The Urban Employee Basic Medical Insurance (UEBMI) covers the general working class and one thing worth to noting is its mandatory nature. Premium is $8 \%$ of an employee'swage of which $6 \%$ is contributed by employer and it provides a generally higher medical coverage. The Urban Residents Basic Medical Insurance (URBMI) is a household-levelvoluntary medical insurance for those not covered by UEBMI, including children, students and other nonworking residents. ${ }^{4,5}$ Despite the enormous effort, shortfalls still exist in certain aspects such as protection coverage and effectiveness.

In this study we aim to investigate real-life problems encountered by MDR-TB patients in three generally mid- to high-income cities, identify major difficulties and suggest ways to tackle them via public health policy enhancements. The goal is to achieve higher cure rates and lower transmission rates through improving the overall wellbeing of these patients.

\section{Materials and Methods}

\section{Study Population}

Beijing is the capital of China. Shenzhen is a special administrative region and enjoys a prime geographic location. Jiangmen is part of the Guangdong province and is benefitting from its fast development. These 3 cities are characterized by a relatively high GDP with a correspondingly high cost of living. ${ }^{8}$

With the launch of The Chinese Infectious and Endemic Disease Control (IEDC) TB Project in 1991 and the adoption of the TB DOTS strategy, patients diagnosed with TB are treated at one of these three types of hospitals: (a) TB-designated hospital, provides health care for tuberculosis cases only; (b) an infectious diseases hospital, provides care for TB and other infectious disease, such as cases involving hepatitis, HIV, etc.; (c) a general hospital that provides health care for treating various diseases, but with a dedicated ward for care of TB patients. ${ }^{9}$

In this study, the participating hospitals are classified as follows - The Chest Hospital of Peking is a type (c) hospital, Jiangmen Institute of Tuberculosis Prevention and Control is a type (a) hospital and The Third People's hospital of Shenzhen is a type (b) hospital.

A total of 144 newly-diagnosed MDR-TB patients were recruited from three hospitals from the three cities, from January 1 to April 30 in 2017. Sixty-seven cases were excluded as 38 of them were lost to follow-up and 29 patients refused to participate, leaving 77 patients in this study. Patients recruited in this study did not represent the total number of MDR-TB cases in these three cities. Face-to-face and phone-call interviews were conducted by their TB clinicians in early 2018. (Figure 1). All participants, including those who did phone interviews, were informed about the purpose of the study before participating. The participants who did the face-to-face interviews provided informed consent on the spot and those who did the phone-call interviews confirmed informed consent at clinic during follow-up visit. This study was approved by The Ethics Committee of The Third People's Hospital for the National Key Project for Infectious Disease and complied with the Declaration of Helsinki.

\section{Questionnaire Design}

The questionnaire was designed to focus on the following aspects: (1) sociodemographic characteristics, (2) medical condition and care received, (3) difficulties encountered, (4) family financial situation and insurance coverage, (5) amount spent on medical expenses and (6) adherence to suggested community care (home isolation) schedule. Sociodemographic characteristics included age, gender, marital status, occupation and education level. Medical conditions were presented in the form of length of hospitalization and result of sputum smear on diagnosis. Questions to measure the difficulties faced included financial hardship, fear of syringe injection, inconvenience in clinic visit trips, adverse reaction to prescribed drugs and psychological pressure. Patients were free to quote more than one problem. Questions to measure household economic conditions and medical expenses incurred included type of insurance and coverage, monthly self-pay amount on TB medications and adherence level of suggested community care schedule were reflected by questions on when these patients returned to work (Supplementary Material). Patients who returned to work upon home-discharge or 


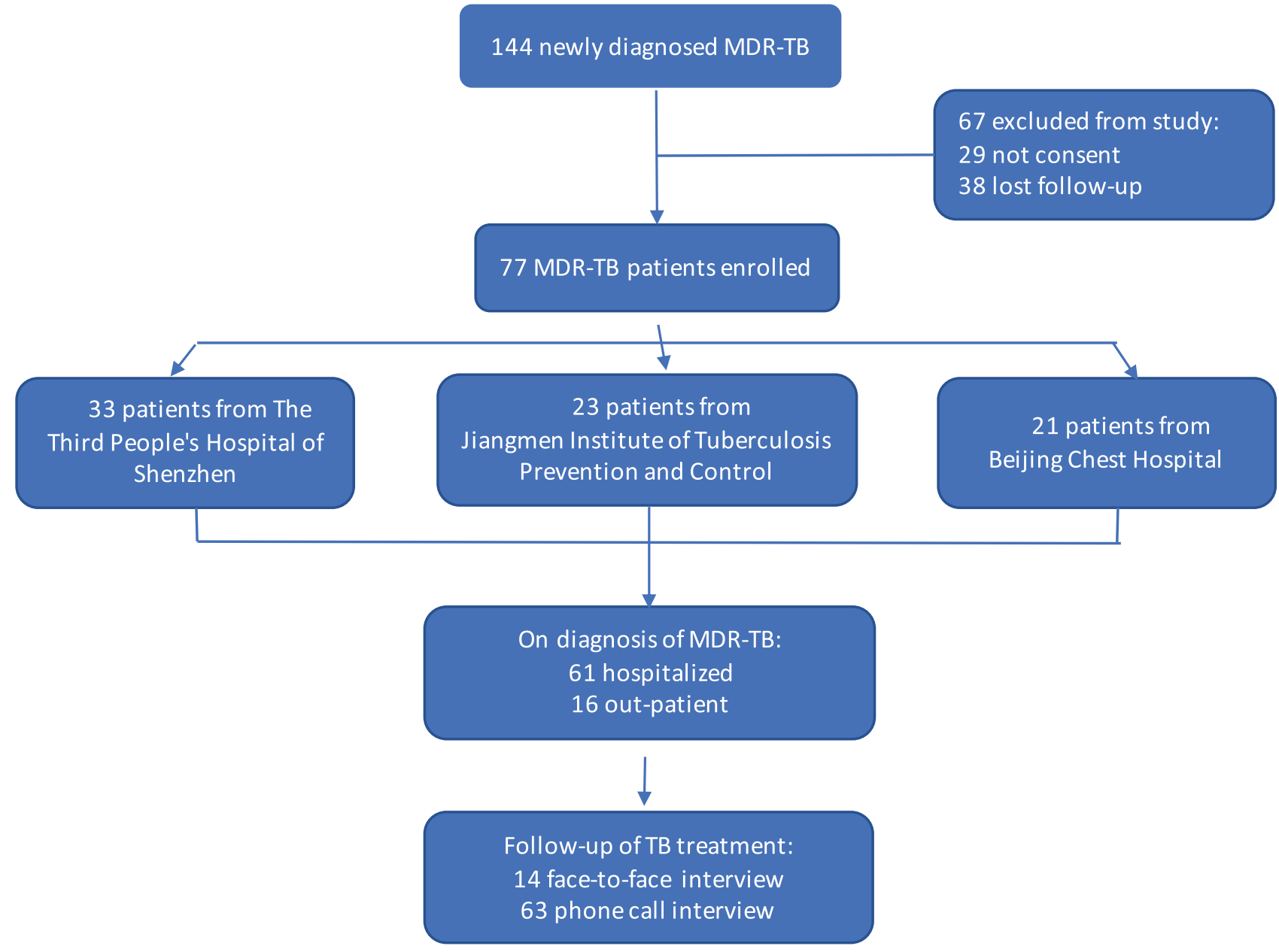

Figure I Flowchart of case recruitment in this study.

who participated in social activities immediately afterwards were considered failed community care.

\section{Statistics Analysis}

Data analysis was conducted using Statistical Analysis System (SAS) version 9.2, (SAS Institute, Cary, NC. USA). $P$-values were reported to assess the statistical significance $(p<0.05)$ of the difference.

\section{Results}

\section{Demographic Characteristic}

A total of 77 adult patients comprising 56 males and 21 females were interviewed in this study. Among them 65\% were under 50 years old, $70 \%$ were married and $70 \%$ were non-local patients. In terms of occupation, $53 \%$ of them were working class (including worker/farmer and white collar/officer/specialist), $36 \%$ of them were part-time workers or unemployed. Proportion of patients who ignored community care and returned to work on hospital discharge were $48 \%$ in married persons, $56 \%$ in white collar workers and $43 \%$ in temp jobs/unemployed persons. (Table 1)

\section{Medical Care Received}

A total of 79\% (61) of the patients were hospitalized after MDR-TB diagnosis with an average hospital stay of 14 days; $74 \%$ (57) of patients were sputum positive on diagnosis. (Table 2)

\section{Insurance Coverage}

In our study, $26 \%$ (20) of the patients were covered by NRCMS, 53\% (41) covered by UEBMI and URBMI, only $1 \%$ (1) was covered by commercial insurance, while $20 \%$ (15) had not bought any medical insurance for themselves. The less an individual is covered by insurance, the more is their self-borne medical expenses. The proportion of patients who failed 
Table I Demographic Characteristics of Patients Who Participated in This Study

\begin{tabular}{|c|c|c|c|c|c|}
\hline Characteristics & $\begin{array}{l}\text { No. of } \\
\text { Patients }\end{array}$ & $\begin{array}{l}\text { Proportion of Total No. } \\
\text { of Patients (\%) }\end{array}$ & $\begin{array}{l}\text { No. of Patients Failed } \\
\text { Community Care } * *\end{array}$ & $\begin{array}{l}\text { Proportion of the } \\
\text { Group (\%) }\end{array}$ & $p$-value \\
\hline \multicolumn{6}{|l|}{ Gender } \\
\hline Male & 56 & $73 \%$ & 18 & $32 \%$ & 0.2 \\
\hline Female & 21 & $27 \%$ & 10 & $48 \%$ & \\
\hline \multicolumn{6}{|l|}{ Age } \\
\hline $18-35$ & 29 & $38 \%$ & 6 & $21 \%$ & 0.09 \\
\hline $36-50$ & 21 & $27 \%$ & 10 & $48 \%$ & \\
\hline$>51$ & 27 & $35 \%$ & 12 & $44 \%$ & \\
\hline \multicolumn{6}{|l|}{ Marital status } \\
\hline Single/Divorced/Widowed & 23 & $27 \%$ & 2 & $9 \%$ & 0.001 \\
\hline Married & 54 & $70 \%$ & 26 & $48 \%$ & \\
\hline \multicolumn{6}{|l|}{ Residency } \\
\hline Local & 23 & $30 \%$ & 10 & $43 \%$ & 0.4 \\
\hline Non-local & 54 & $70 \%$ & 18 & $33 \%$ & \\
\hline \multicolumn{6}{|l|}{ Occupation } \\
\hline Student & 8 & $10 \%$ & 0 & $0 \%$ & 0.09 \\
\hline Worker/Farmer & 23 & $30 \%$ & 6 & $26 \%$ & \\
\hline White Collar/Officer/ & 18 & $23 \%$ & 10 & $56 \%$ & \\
\hline Specialist & & & & & \\
\hline $\begin{array}{l}\text { Others (temp jobs/part-time } \\
\text { jobs/unemployed) }\end{array}$ & 28 & $36 \%$ & 12 & $43 \%$ & \\
\hline \multicolumn{6}{|l|}{ Education level } \\
\hline Primary & 9 & $12 \%$ & 4 & $44 \%$ & 0.5 \\
\hline Junior high school & 25 & $32 \%$ & 10 & $40 \%$ & \\
\hline Senior high school & 24 & $31 \%$ & 10 & $42 \%$ & \\
\hline College* & 19 & $25 \%$ & 4 & $21 \%$ & \\
\hline
\end{tabular}

Notes: *All students are in this group. **All home-discharged MDR-TB patients were recommended to be on community care (including self-quarantine) until culture conversion. Going to work and participating in social activities were considered failing community care.

Table 2 Medical Care for Patients Who Participated in This Study

\begin{tabular}{|c|c|c|c|c|c|}
\hline Characters & $\begin{array}{l}\text { Total } \\
(n=77)\end{array}$ & $\begin{array}{l}\text { Proportion of } \\
\text { Total (\%) }\end{array}$ & $\begin{array}{l}\text { No. of Patients Failed } \\
\text { Community Care }\end{array}$ & $\begin{array}{l}\text { Proportion of the } \\
\text { Group (\%) }\end{array}$ & $p$-value \\
\hline Sputum smear & & & & & 0.9 \\
\hline- & 20 & $26 \%$ & 7 & $35 \%$ & \\
\hline+ & 31 & $40 \%$ & 11 & $36 \%$ & \\
\hline++ & 7 & $9 \%$ & 3 & $43 \%$ & \\
\hline+++ & 19 & $25 \%$ & 7 & $37 \%$ & \\
\hline Hospitalized & & & & & 0.2 \\
\hline Yes & 61 & $79 \%$ & 20 & $33 \%$ & \\
\hline No & 16 & $21 \%$ & 8 & $50 \%$ & \\
\hline Average hospitalized period (Days) & 14 & & & & \\
\hline
\end{tabular}

community care were $23 \%$ with no insurance and/or NRCMS and 45\% with UEBMI/URBMI and commercial insurance. (Table 3)

\section{Difficulties Faced During Treatment}

During MDR-TB treatment, patients encountered a range of difficulties including financial pressure (43\%), psychological 
Table 3 Insurance Coverage of Patients Who Participated in This Study

\begin{tabular}{|l|l|l|l|l|}
\hline Type of Insurance & $\begin{array}{l}\text { Total } \\
(\mathbf{n = 7 7 )}\end{array}$ & $\begin{array}{l}\text { Proportion of } \\
\text { Total (\%) }\end{array}$ & $\begin{array}{l}\text { No. of Patients Failed } \\
\text { Community Care }\end{array}$ & $\begin{array}{l}\text { Proportion of the } \\
\text { Group (\%) }\end{array}$ \\
\hline None (all out-of-pocket expenses) & 15 & $20 \%$ & 3 & $20 \%$ \\
NRCMS & 20 & $26 \%$ & 5 & $25 \%$ \\
UEBMI/URBMI & 41 & $53 \%$ & 19 & $46 \%$ \\
Commercial Insurance & $\mathrm{I}$ & $1 \%$ & 1 & $100 \%$ \\
\hline
\end{tabular}

Abbreviations: NRCMS, New Rural Co-operative Medical Scheme; UEBMI, Urban Employee Basic Medical Insurance; URBMI, Urban Residents Basic Medical Insurance.

stress (34\%), adverse drug reactions (30\%), and repulsiveness towards the use of syringe injections (23\%). (Figure 2)

\section{Financial Burden}

On average, out-of-pocket medical costs for $48 \%$ (37) MDR-TB patients were over USD300 per month on treatment, among them, 35\% (13) failed community care,; $29 \%$ (22) patients incurred costs of between USD150-300 per month and $45 \%$ (10) of them failed community care; $23 \%$ (18) patients spent an additional less than USD150 per month and $28 \%$ (5) of these patients returned to work during suggested home isolation care. (Figure 3)

\section{Discussion}

MDR-TB poses a huge challenge to public health systems in terms of treatment costs and disease control. ${ }^{10}$ In 2012, the China government laid out a program for the treatment and care of MDR-TB, suggesting hospitalization and community care for patient management. It is recommended that patients be hospitalized at a dedicated TB hospital for about 2 months, followed by community care until treatment completion. ${ }^{11}$ Community care involves home visits within $72 \mathrm{hrs}$ for newly diagnosed patients with guidance on recommended home (self)-isolation schedule, and care for the disease and co-habiting family members, and reminders on medication taking and medical check-ups. The aim was to achieve better treatment adherence and reduce household and community transmission. However, this was constrained by the variance of medical resources, infrastructure and their availability in different areas of China. Home isolation schedule adherence is also poor due to catastrophic costs associated with the disease. ${ }^{12}$ While lots of studies have focused on how catastrophic costs associated with MDR-TB impacts patients from low

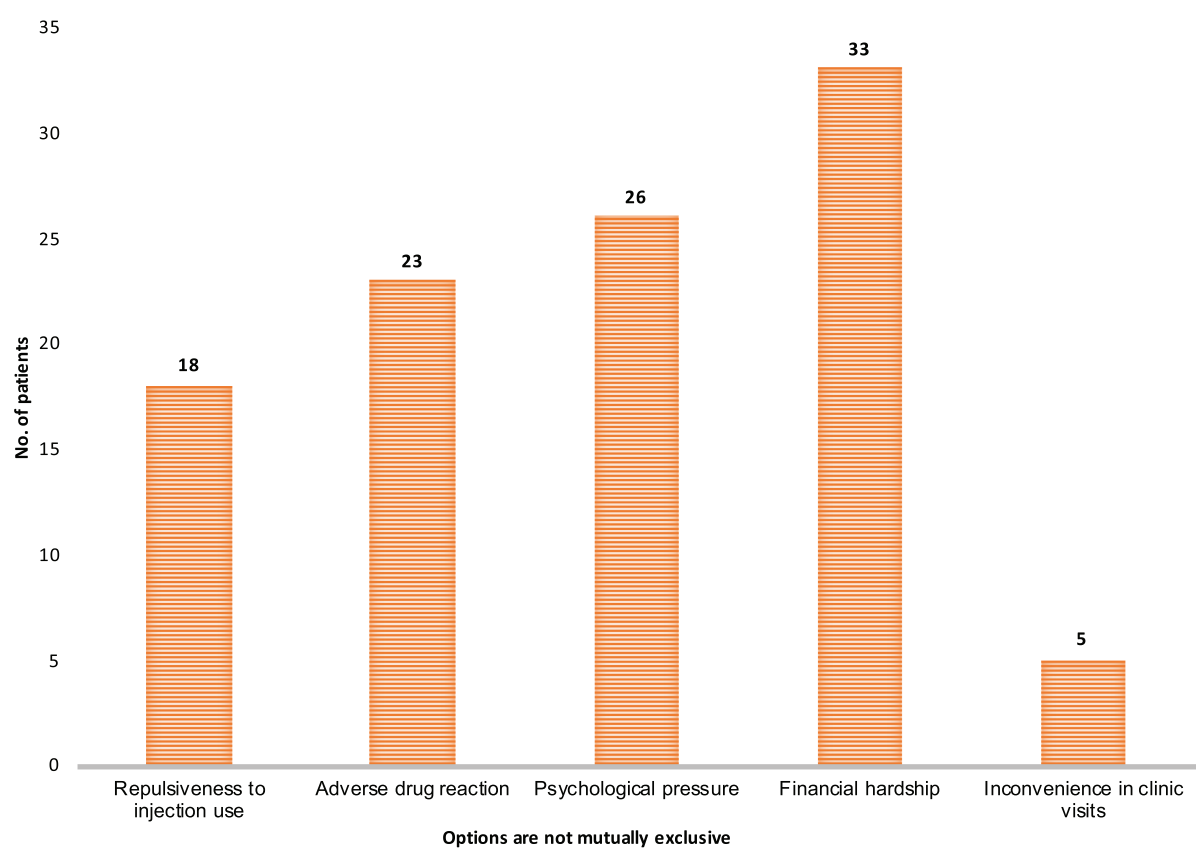

Figure 2 Problems faced by MDR-TB patients. 


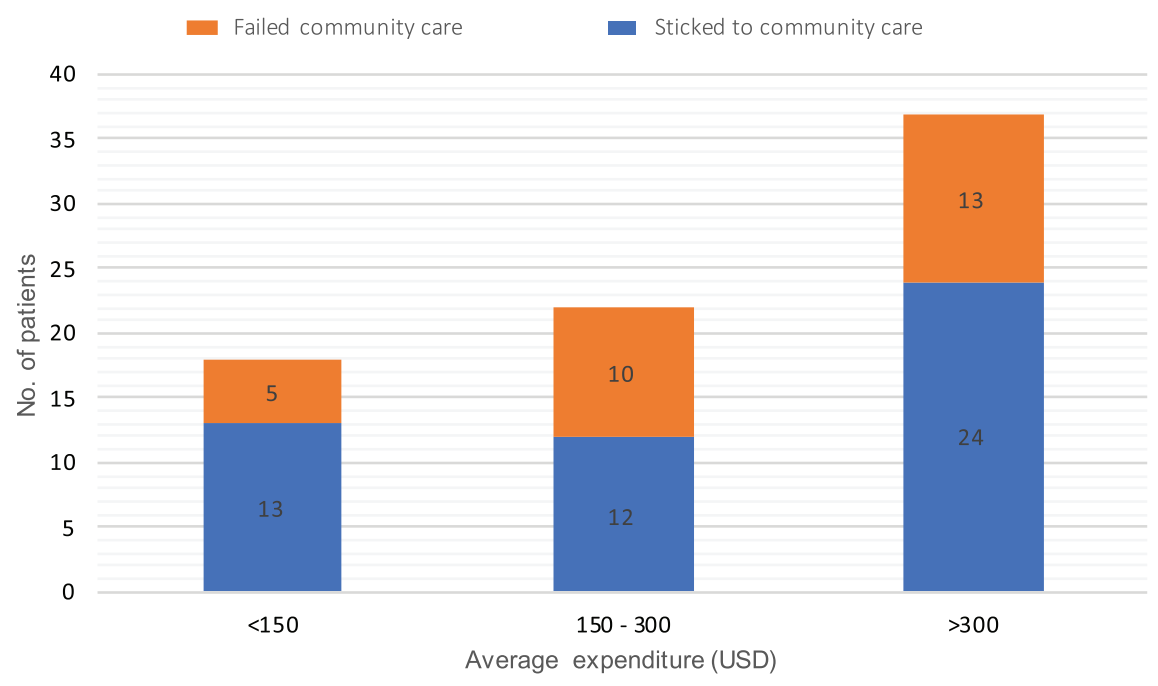

Figure 3 Monthly out-of-pocket medical cost for MDR-TB patients.

income countries, we conducted a survey with enrollment from three mid- to high-income cities of China to review and identify potential factors and their impacts on city patients. Suggestions on improving and enhancing future policy design were then made based on the findings.

\section{Financial Hardship and Catastrophic Cost}

The costs for treating MDR-TB were reported to range from US $\$ 1218$ to US $\$ 83,365$ per case. ${ }^{10,13}$ This includes treatment cost, and other indirect costs such as transport costs and income loss. Potential loss of insurance coverage as a result of job loss could further aggravatedthese patients' financial burden. Despite constant efforts the China Government in health care measures, trying to ease financial burden, a substantial portion of MDR-TB patients reflected that one of the major problems from the illness was still financial hardship. ${ }^{14-16}$ Many kinds of medicines are not provided free of charge, especially new effective medicines such as linezolid and cycloserine. Numerous studies have proven total costs spent on treating MDR-TB is catastrophic for patients from most low- to middle-income families. ${ }^{17,18}$ Surprisingly we found the working class were struck the hardest financially in cities. Their relatively high cost of living, with an expensive-to-treat disease left them with a drained disposable household income. Their urge to return to work despite treatment status was the most alarming among all income groups. This is especially true for those who were married and were the breadwinner as reflected in our cohort. Out of the 28 patients who failed community care, $26(93 \%)$ were married (Table 1). Findings in our study showed a substantial difference in the ratio between the married (48\%) and single (9\%) participants in returning to work during the suggested home-isolation period.

Our study showed a direct relationship between the proportion of patients failing community care and the increase in foreseeable self-borne medical expenses. From the perspective of insurance coverage, $100 \%$ of patients obtaining self-paid commercial insurance and $46 \%$ of patients under UEBMI/URBMI returned to work during the suggested self-isolation period: “ Being out of a job means my family will not have enough income and I will no longer be covered by URBMI, and I cannot afford the premium for commercial insurance on my own". Without insurance coverage, I have to absorb all costs of medical treatment. My family simply cannot afford this".

A MDR-TB patient who worked as a taxi driver told us: that under UEBMI, employer has to pay $75 \%$ of premium for the employee, if one is out of job, they would have to bear full premium in keeping the insurance. The same correlation has been derived from out-of-pocket expenses. GDP per capita in China was USD7346.6 in 2017 and USD7807 in $2018 .{ }^{19}$ When monthly expenditure went above USD150, over one third of patients chose to return to work despite the suggested home isolation care. This is true for patients under all kinds of insurance except NRCMS. The reason behind this could be the cost of keeping the insurance coverage. Premium for NRCMS is only USD4.5/year which is way below any other insurance premium included in this study. In combating this problem, the government could consider full medical coverage for MDR-TB patients, through special TB protection and registration programs, to enable expenses to be credited directly to the government, or 
an appointed agent. This can simplify the application and reimbursement process made on a per visit basis, and sooth patients fundamental financial difficulty.

\section{Problems Faced During Treatment and Possible Solutions}

Although WHO had downregulated the importance of second-line injections in 2018, it was still widely used in many MDR-TB regimens in China in 2017. ${ }^{20,21}$ When new drugs are unavailable, clinicians will resort to injection to construct part of an effective regimen. The pain and uncomfortable experience with injection discouraged most patients from adhering to treatment. And deficient regimen and insufficient treatment are among the main causes which led to more drug resistance and treatment failure. ${ }^{22,23}$

Furthermore, most anti-MDR-TB drugs have obvious toxic side effects which cause treatment adherence failure. A 62-year-old female MDR-TB patient in our study has stopped treatment on her own several times. Her current drug sensitivity test turned out to be XDR-TB. In addition, most MDR-TB patients suffer from severe psychological stress. ${ }^{24,25}$ Worrisome thoughts included their illness being difficult to cure and the fear of spreading the disease to their family and friends. At the same time, they also worried about being isolated and alienated by their friends and family. Providing care providers with free TB drugs and patients with new and effective oral medications, counselling service, and organizing patient groups to share experience will help them get the emotional support they need to complete treatment. This in turn would reduce disease spreading and minimize drug-resistance TB to be further developed.

\section{Risk of Transmission from Home-Discharged Patients}

It has been reported that pooled treatment success was about $60 \%$ in MDR-TB patients. ${ }^{26,27}$ In the absence of new drugs such as bedaquiline, delamanid and linezolid, the success of treatment outcomes for MDR-TB with standardized secondline regimen in China before 2018 was only about $50 \%{ }^{28}$ Recent studies from China using genomic epidemiological approach have shown that new infection was the main cause of MDR-TB. ${ }^{29,30}$ Our study showed that about $80 \%$ (61) MDR-TB of patients were hospitalized and 74\% (57) of them were smear positive at the time of inpatient admission. Average hospital stay for these patients was 2 weeks, which is below the suggested length of inpatient care. Furthermore, most patients returned to work and participated in social activities during the period of self-isolation. It is unclear how many of the patients still on treatment were contributing to the spread of the disease, but the risk of transmission is a challenge that needs to be addressed immediately.

There were some limitations in our study. Firstly, the participants were only from three cities therefore are not representative of all MDR-TB patients. The lack of control groups hindered comparisons with other population groups. Secondly, the high percentage of patients refusing to be interviewed or lost to follow-up were also considered as having a high likelihood of treatment drop-out, which may have contributed to a loss of important relevant information and caused selection bias leading to underestimation of the difficulties the overall MDR-TB patients are facing. Thirdly, the study had not measured the risk of disease transmission from these patients who were currently under-treatment for $\mathrm{TB}$, therefore no conclusions can be drawn on the relationship between airborne risk spread by the said patients in the current study.

\section{Conclusion}

In summary, MDR-TB patients encountered great hardship in relatively financially affluent cities despite insurance coverage, creating a major obstacle in treatment adherence., as poverty and TB control has long been proved to have an inverse correlation. Tackling the problem must start from the root cause to alleviate caseload, all the way up to followup management of patients to minimize transmission and disease progression. Funding, free effective new oral medicine, provision of patient-centered support and performancelinked incentives together can mark a major step towards disease control and treatment success for TB.

\section{Data Sharing Statement}

All original data used in the study has been de-identified and are available on line from the corresponding author by request.

\section{Acknowledgments}

The authors are grateful for the continued academic support from The National Clinical Research Center for Infectious Disease in China and China Tuberculosis Clinical Trial Consortium (CTCTC).

\section{Funding}

This work was supported financially by the 13th Five-Year National Key Projects for infectious disease (2018ZX10715004-002-007) and was supported by Science Research foundation of Guangdong Province (B2018045). 


\section{Disclosure}

The authors report no conflicts of interest in this work.

\section{References}

1. World Health Organization. Global tuberculosis report 2019. 2019.

2. Haileamlak A. Infectious diseases continued to be the world's core challenge. Ethiop J Health Sci. 2017;27(6):570. doi:10.4314/ejhs. v27i6.1

3. Meng Q, Xu K. Progress and challenges of the rural cooperative medical scheme in China. Bull World Health Organ. 2014;92 (6):447-451.

4. Pan XF, Xu J, Meng Q. Integrating social health insurance systems in China. Lancet. 2016;387(10025):1274-1275. doi:10.1016/S01406736(16)30021-6

5. Meng Q, Fang H, Liu X, Yuan B, Xu J. Consolidating the social health insurance schemes in China: towards an equitable and efficient health system. Lancet. 2015;386(10002):1484-1492. doi:10.1016/ S0140-6736(15)00342-6

6. Li C, Hou Y, Sun M, et al. An evaluation of China's new rural cooperative medical system: achievements and inadequacies from policy goals. BMC Public Health. 2015;15:1079.

7. Yuan B, Jian W, He L, Wang B, Balabanova D. The role of health system governance in strengthening the rural health insurance system in China. Int J Equity Health. 2017;16(1):44. doi:10.1186/s12939017-0542-x

8. Yi Wen. Income and living standards across China. January 8, 2018. Available from: https://www.stlouisfed.org/on-the-economy/2018/jan uary/income-living-standards-china. Accessed October 28, 2020.

9. Liu Y, Pang Y, Du J, et al. An overview of tuberculosis-designated hospitals in China, 2009-2015: a longitudinal analysis of national survey data. Biomed Res Int. 2019;2019:9310917.

10. Tanimura T, Jaramillo E, Weil D, Raviglione M, Lonnroth K. Financial burden for tuberculosis patients in low- and middle-income countries: a systematic review. Eur Respir J. 2014;43(6):1763-1775.

11. Wang Y The management of pulmonary multi-drug resistant tuberculosis. (in Chinese).

12. Tang S. Tackling challenges of TB/MDRTB in China: concerted actions are imperative. Infect Dis Poverty. 2015;4:19.

13. Diel R, Vandeputte J, de Vries G, Stillo J, Wanlin M, Nienhaus A. Costs of tuberculosis disease in the European Union: a systematic analysis and cost calculation. Eur Respir J. 2014;43(2):554-565. doi:10.1183/09031936.00079413

14. Long Q, Smith H, Zhang T, Tang S, Garner P. Patient medical costs for tuberculosis treatment and impact on adherence in China: a systematic review. BMC Public Health. 2011;11:393. doi:10.1186/ 1471-2458-11-393

15. Hutchison C, Khan MS, Yoong J, Lin X, Coker RJ. Financial barriers and coping strategies: a qualitative study of accessing multidrug-resistant tuberculosis and tuberculosis care in Yunnan, China. BMC Public Health. 2017;17(1):221.
16. Long Q, Qu Y, Lucas H. Drug-resistant tuberculosis control in China: progress and challenges. Infect Dis Poverty. 2016;5:9.

17. Zhou C, Long Q, Chen J, et al. Factors that determine catastrophic expenditure for tuberculosis care: a patient survey in China. Infect Dis Poverty. 2016;5:6. doi:10.1186/s40249-016-0100-6

18. Chen S, Zhang H, Pan Y, et al. Are free anti-tuberculosis drugs enough? An empirical study from three cities in China. Infect Dis Poverty. 2015;4:47. doi:10.1186/s40249-015-0080-y

19. China GDP per capital, 1960-2019 data. Trading Economic. Available from: https://radingeconomics.com/china/gdp-percapita. Accessed October 28, 2020.

20. Anti-tuberculosis association of China. Guideline of Chemotherapy for multi-drug resistance tuberculosis (2015) (in Chinese). Zhongguo Fang Lao Za Zhi. 2015;37(5):421-469.

21. World Health Organization. WHO treatment guidelines for drugresistant tuberculosis (2016 update). 2016.

22. Wu S, Zhang Y, Sun F, et al. Adverse events associated with the treatment of multidrug-resistant tuberculosis: a systematic review and meta-analysis. Am $J$ Ther. 2016;23(2):e521-530. doi:10.1097/01. mjt.0000433951.09030.5a

23. Javaid A, Ullah I, Masud H, et al. Predictors of poor treatment outcomes in multidrug-resistant tuberculosis patients: a retrospective cohort study. Clin Microbiol Infect. 2018;24(6):612-617. doi:10.1016/j.cmi.2017. 09.012

24. Morris MD, Quezada L, Bhat P, et al. Social, economic, and psychological impacts of MDR-TB treatment in Tijuana, Mexico: a patient's perspective. Int J Tuberc Lung Dis. 2013;17(7):954-960. doi:10. 5588/ijtld. 12.0480

25. Xu M, Markstrom U, Lyu J, Xu L. Survey on tuberculosis patients in rural areas in china: tracing the role of stigma in psychological distress. Int J Environ Res Public Health. 2017;14(10):1171. doi:10. 3390/ijerph14101171

26. Bastos ML, Lan Z, Menzies D. An updated systematic review and meta-analysis for treatment of multidrug-resistant tuberculosis. Eur Respir J. 2017;49(3).

27. Collaborative Group for the Meta-Analysis of Individual Patient Data in MDRTBt; Ahmad N, Ahuja SD, Akkerman OW, et al. Treatment correlates of successful outcomes in pulmonary multidrug-resistant tuberculosis: an individual patient data meta-analysis. Lancet. 2018;392(10150):821-834. doi:10.1016/S0140-6736(18)31644-1.

28. Xu C, Pang Y, Li R, et al. Clinical outcome of multidrug-resistant tuberculosis patients receiving standardized second-line treatment regimen in China. J Infect. 2018;76(4):348-353. doi:10.1016/j. jinf.2017.12.017

29. Yang C, Shen X, Peng Y, et al. Transmission of Mycobacterium tuberculosis in China: a population-based molecular epidemiologic study. Clin Infect Dis. 2015;61(2):219-227.

30. Yang C, Luo T, Shen X, et al. Transmission of multidrug-resistant Mycobacterium tuberculosis in Shanghai, China: a retrospective observational study using whole-genome sequencing and epidemiological investigation. Lancet Infect Dis. 2017;17(3):275-284. doi:10.1016/S1473-3099(16)30418-2
Risk Management and Healthcare Policy

\section{Publish your work in this journal}

Risk Management and Healthcare Policy is an international, peerreviewed, open access journal focusing on all aspects of public health, policy, and preventative measures to promote good health and improve morbidity and mortality in the population. The journal welcomes submitted papers covering original research, basic science, clinical \& epidemiological studies, reviews and evaluations, guidelines, expert opinion and commentary, case reports and extended reports. The manuscript management system is completely online and includes a very quick and fair peer-review system, which is all easy to use. Visit http://www.dovepress.com/testimonials.php to read real quotes from published authors. 